\title{
Clinical and ultrasonographic criteria for using ventriculoperitoneal shunts in newborns with myelomeningocele
}

\author{
Critérios clínicos e ultrassonográficos para a indicação de derivação ventrículo peritoneal
} em neonatos portadores de mielomeningocele

Jose Roberto Tude Melo', Pollyana Pacheco', Emília Nunes de Melo', Ângela Vasconcellos', Rosane Klein Passos²

\begin{abstract}
Objective: Hydrocephalus is one of the main complications associated with myelomeningocele (MM). This study aimed to identify clinical and ultrasonographic criteria for using ventriculoperitoneal (VP) shunts in this group of patients. Method: A retrospective cohort study, based on established protocol for VP shunt implant in hydrocephalic children with MM. Parameters used to guide the indication of VP shunts included measurement of head circumference (HC), evaluation of fontanels, and measurement of lateral ventricular atrium (LVA) width by transcranial ultrasonography. Results: 43 children were included in the analysis, of which $74 \%$ had hydrocephalus and required a VP shunt. These children had LVA width $\geq 15 \mathrm{~mm}$, showed increased HC, or had bulging fontanels. Conclusion: VP shunt is required in children with increased $\mathrm{HC}$ ( $\geq 2$ standard deviation regarding age group), bulging fontanels, or LVA width of $\geq 15 \mathrm{~mm}$ after the closure of MM.
\end{abstract}

Keywords: hydrocephalus, epidemiology, congenital abnormalities, myelomeningocele.

\section{RESUMO}

Objetivo: Identificar os critérios clínicos e ultrassonográficos para a recomendação do implante de derivações ventrículo peritoneais (DVP) em neonatos portadores de mielomeningocele (MM). Método: Estudo de coorte retrospectivo, com base no protocolo estabelecido para o implante de DVP em crianças com hidrocefalia associada a MM. Parâmetros utilizados para orientar a indicação de DVP incluíram a medida da circunferência craniana (CC), a avaliação das fontanelas e a medida da largura lateral do átrio ventricular (LAV), avaliado por ultrassonografia transcraniana. Resultados: 43 crianças foram incluídas na análise, dos quais 74\% tinham hidrocefalia com recomendações para uso de DVP. Conclusão: 0 aumento da CC e o abaulamento de fontanelas foram os principais critérios para a indicação de DVP. A DVP é necessária em crianças com aumento da CC ( $\geq 2$ desvios padrões para a idade), fontanelas abauladas, ou LAV $\geq 15 \mathrm{~mm}$ após o fechamento cirúrgico da MM.

Palavras-chave: hidrocefalia, epidemiologia, anormalidades congenitas, mielomeningocele.

Myelomeningocele (MM) is the most common form of spinal dysraphism being the complex congenital malformation of the central nervous system (CNS) compatible with life, of higher incidence ${ }^{1,2,3,4}$. Despite prophylactic measures, such as use of folic acid before and during pregnancy ${ }^{5,6}$, incidence of MM remains high, ranging between 0.1 and 10 per 1,000 live births ${ }^{1,7}$. Moreover, MM is more common in countries showing low socioeconomic development ${ }^{8}$. According to the World Health Organization, among 41 evaluated countries, Brazil ranks fourth in the incidence of spina bifida, at a rate of 1.1:1,000 live births ${ }^{7.8}$. Hydrocephalus is present in most children with $\mathrm{MM}^{7,9}$, thus making it essential to establish criteria for indicating ventriculoperitoneal (VP) shunts in these children ${ }^{9,10,11,12}$.

Brazil is a large country with socioeconomic imbalance ${ }^{13}$ and poor accessibility to radiological methods of diagnosis, such as computed tomography (CT) or magnetic resonance imaging (MRI), for routine examination of neonates with neurological diseases in public health hospitals, which makes it difficult to apply standardized protocols followed in developed countries ${ }^{9,11,14}$. This study aimed to describe the epidemiological profile of children with MM by considering the records of a public pediatric reference hospital and identify clinical and transcranial ultrasonographic criteria for the indication of VP shunts in these children.

${ }^{1}$ Hospital Martagão Gesteira, Unidade de Neurocirurgia Pediátrica, Salvador BA, Brazil;

${ }^{2}$ Hospital Martagão Gesteira, Unidade de Radiologia, Salvador BA, Brazil.

Correspondence: Jose Roberto Tude Melo; Rua Jose Duarte, 114; 40000-000 Salvador BA, Brasil; E-mail: robertotude@martagaogesteira.org.br Conflict of interest: There is no conflict of interest to declare.

Support: Fundação de Amparo à Pesquisa do Estado da Bahia (FAPESB) for financial support in a part of this research (disclosure of results).

Received 03 November 2014; Received in final form 29 April 2015; Accepted 18 May 2015 


\section{METHOD}

This research was approved by the Brazilian Research Ethics Committee (registration number 14990213.5.0000.5543).

This retrospective cohort study included the medical records of all newborns who underwent surgical closure of $\mathrm{MM}$ at a reference public pediatric hospital in Salvador da Bahia, Brazil, between 2009 and 2013. All the children included in this study underwent the same protocol for hydrocephalus in case of MM, as those described in previous reports ${ }^{9,11,12}$. Transcranial ultrasonography (TUS) was chosen as the radiological method for diagnosing hydrocephalus in all neonates, as that described in previous studies $^{15,16,17}$, because of the difficulty in performing CT scan or MRI in these children. TUS was performed with a 1.9- to $6 \mathrm{MHz}$ curvilinear transducer (Toshiba Aplio $100^{\circ}$ with color Doppler), with a classical trans-fontanelar window approach by a trained operator (senior radiologist with $>10$ years experience in TUS).

Based on previously established measurements, a neonate was considered as having mild hydrocephalus when the transversal lateral ventricular atrium (LVA) width, measured slightly above the level of the thalami at the level of the choroid plexus, was $<15 \mathrm{~mm}(10-14 \mathrm{~mm})^{18}$. When this value was $\geq 15 \mathrm{~mm}$ (15-19mm), the neonate was considered as having moderate hydrocephalus ${ }^{18}$. Thus, the study population was divided into two groups:

- Group A: Children with LVA width of $<15 \mathrm{~mm}(\mathrm{n}=12)$

- Group B: Children with LVA width of $\geq 15 \mathrm{~mm}(\mathrm{n}=31)$

Because hydrocephalus mostly develops in the first 43 days after the closure of $\mathrm{MM}^{9}$, we recommended a biweekly follow-up during the first two months after the closure of MM to measure head circumference (HC) and LVA width (by TUS). We consider the measure of $\mathrm{HC}$ and evaluation of the fontanels as the most important clinical signs to be observed in these children, according to previously published studies $^{11,15,16,17,19}$. Infant girls with HC of $37.7 \mathrm{~cm}$ and infant boys with $\mathrm{HC}$ of $38.5 \mathrm{~cm}$ who showed an increase in the ventricular system were considered as having hydrocephalus since birth $^{17,18,20}$. In this group, the proposal for treatment was of closure of MM and VP shunt at the same surgical time. VP shunt was chosen as the method of choice for treating hydrocephalus in these children after considering the benefits and drawbacks of endoscopic third ventriculostomy (ETV) in neonates with $\mathrm{MM}^{12,17,21}$.

\section{Statistical analyses}

Based on previous study on the incidence of hydrocephalus in children with $\mathrm{MM}^{9}$, our study included 43 children, considering a sampling error of $5 \%$ and a confidence interval of $95 \%$. Some results were exposed in descriptive manner, dispensing statistical analyses. Measures of central tendency (mean, mode, and median) were calculated and presented where relevant. We compare groups (exposed and control groups) and verified the odds ration. The differences were considered statistically significant when $\mathrm{p}<0.05$ (Z statistic test). The sensibility, specificity, predictive values and efficiency (the proportion of correct predictions; sum of true positives and true negatives) were calculated, considering the LVA width, $15 \mathrm{~mm}$ cutoff point.

\section{RESULTS}

Forty-seven newborns with MM were admitted for treatment during the proposed period. Six newborns (14\%) were considered premature (<37 weeks' gestation). Follow-up was irregular in 4 babies; therefore, they were excluded from the final analysis. Forty-three newborns were consecutively included in the study. Nineteen mothers (44\%) received regular prenatal care ( $\geq 6$ medical appointments) that involved regular folic acid replacement during pregnancy and $70 \%$ came from the coutryside area. Eleven mothers (25\%) underwent a transvaginal delivery. Our hospital did not have a maternity unit (obstetric department), and all the children were transferred from other hospitals usually $24 \mathrm{~h}$ after birth. Among the newborns included in this study, $51 \%$ were boys and $95 \%$ had lumbar and lumbosacral lesions. MM was present as a ruptured lesion in $50 \%$ of our sample. Intrauterine corrections were not performed for the closure of MM in our hospital until the end of this research. Table 1 shows the main epidemiological aspects of children with MM that were evaluated in this study.

The overall incidence of hydrocephalus and the need of VP shunts were observed in 32 (74\%) children. LVA width was measured by performing TUS at 48-72h after the closure of MM. VP shunt were required in 50\% (6/12) children with an LVA width of < $15 \mathrm{~mm}$ (group A) and in 84\% (26/31) children with an LVA width of $\geq 15 \mathrm{~mm}$ (group $\mathrm{B}$; $\mathrm{p}=0.02$; $\mathrm{OR}=5.2$ ). Evaluating the sensitivity and specificity of LVA width as a measure to guide the indication of VP-shunt, we found sensitivity of $81 \%$, a positive predictive value of $84 \%$, and efficiency of $75 \%$ considering $15 \mathrm{~mm}$ cutoff value (Table 2).

Progressive increase in $\mathrm{HC}$ and bulging fontanels were the earliest signs of intracranial hypertension (ICH) (observed in 94\% children; 30/32); these signs were predominant in children with LVA width of $\geq 15 \mathrm{~mm}$. In the remaining two children $(6 \% ; 2 / 32)$, VP shunts were indicated based on other signs of ICH such as respiratory distress, hypotonia, and drowsiness; these were consistent with the increases in the ventricular system identified using TUS before hospital discharge. The average duration for the development of hydrocephalus was 35 days (range, 0-180 days) after the closure of MM. Figure shows the protocol for VP shunt in children with MM after considering TUS observations and clinical criteria. Three children simultaneously underwent closure of MM and ventricular drainage because at hospital admission, they had 
Table 1. Epidemiological aspects of 43 children with myelomeningocele (MM) who were treated in a referral pediatric hospital in the state of Bahia, Brazil (2009-2013).

\begin{tabular}{lc}
\hline General Characteristics & $\mathrm{n}(\%)$ \\
\hline Regular prenatal care ( $\geq 6$ medical appointments) & $19(44)$ \\
Regular use of folic acid & $19(44)$ \\
Prenatal diagnosis of MM & $10(23)$ \\
\hline Region of origin & $13(30)$ \\
\hline Capital (city of Salvador da Bahia) & $30(70)$ \\
Rural zone (countryside) & $22(51)$ \\
Males & $32(74)$ \\
\hline
\end{tabular}

a Hydrocephalus requiring a VP shunt.

Table 2. Comparison among the 43 newborns undergoing evaluation by transcranial ultrasonography (TUS) and lateral ventricular atrium (LVA) width, measured slightly above the level of the thalami at the level of the choroid plexus $(15 \mathrm{~mm}$ cutoff), and the need of VP-shunt.

\begin{tabular}{lcc}
\hline \multirow{2}{*}{ TUS } & \multicolumn{2}{c}{ VP shunt } \\
\cline { 2 - 3 } & Yes & No \\
\hline LVA $\geq 15 \mathrm{~mm}$ & 26 & 5 \\
LVA $<15 \mathrm{~mm}$ & 6 & 6
\end{tabular}

We verified a sensitivity of $81 \%$; specificity of $55 \%$; positive predictive value of $84 \%$; a negative predictive value of $50 \%$, and efficiency of $75 \%$, considering the TUS and LVA width measure (15 mm cutoff point).

an $\mathrm{HC}$ above the percentile $90 \%$ corrected for age (HC $\geq 2$ standard deviations for age) and TUS showing an LVA width of $>20 \mathrm{~mm}$ (considered as a severe hydrocephalus).

Three $(7 \%)$ children who underwent surgical closure of MM developed some local problems, as leakage or infection. After VP shunting, complications were observed in $15 \%$ children. The complications were considered to be mechanical in $7.5 \%$ and infectious in the remaining $7.5 \%$ children. Two children who developed mechanical complications associated with VP shunts, which were identified during the follow-up period, underwent ETV. There was a death in our sample, resulting from complications due to Chiari II malformation.

\section{DISCUSSION}

A previous study identified the irregularity and deficiency of prenatal monitoring in pregnant women, assisted by a poor public health system, in the state of Bahia (Brazil) ${ }^{17}$ and indicated that these may be associated with the high incidence of spinal dysraphism ${ }^{5,22,23}$. We recommend, as suggested by other authors, that at least $400 \mu \mathrm{g}$ of a folic acid supplement should be consumed daily; patients with an intermediate to high risk of neural tube defects (such as patients with a previous well-known history of neural tube defects) should consume 4-5 mg folic acid ${ }^{5,22,23}$. Investigation of proposed type of delivery revealed high rates $(25 \%)$ of vaginal delivery. The study suggested that women undergoing transvaginal delivery may receive irregular prenatal care that would consequently lead to the failure of diagnosing $\mathrm{MM}$ in the fetus, which in turn may lead to misguided management based on the type of delivery.Vaginal delivery may increase the risk of rupture and infection of MM during the passage of the fetus from the birth canal; however, indication of cesarean delivery in these pregnant women and its benefits in newborn are still controversial ${ }^{12,24,25}$.

In our study, all the children were transferred from other hospitals in the city of Salvador da Bahia or from a countryside, which is justified by the fact that our hospital is a referral center for treating children with MM in this region. Because of the lack of an obstetric department in our hospital, these children usually arrive at our hospital $24 \mathrm{~h}$ after birth. This delays the immediate closure of the lesions, which should in fact be corrected immediately ${ }^{12}$, and hinders the training of a multidisciplinary team involved in intrauterine closure and correction of $\mathrm{MM}^{1}$. The same situation is observed in other Brazilian states where many maternity hospitals do not have a unit for pediatric neurosurgery, thus making it necessary to transfer these children to other hospitals ${ }^{22,26}$.

The relationship of gender distribution of children with MM can be verified in other studies as well as the preponderance of lumbar and lumbosacral region involvement ${ }^{9,12,26}$. Probably, the fact that all children with MM who were evaluated in this study have awaited transfer for treatment, besides the relatively high number of vaginal delivery, justify the large number of ruptured MM (50\%). MM, particularly when ruptured, must be considered as a neurosurgical emergency because of the high risk of CNS infections ${ }^{12}$, which is a large public health concern in our state. All children with MM undergo surgical closure of the MM as soon as they are transferred to our hospital to prevent the risk of infection and the risk associated with keeping the placode exposed ${ }^{11,12,22,27}$.

Data indicate that the incidence of hydrocephalus and the requirement of VP shunts in these children vary from $52 \%$ to $90 \%$; however, some of these data do not provide a clear definition of the optimal timing and criteria for CSF diversion in children with $\mathrm{MM}^{7,9,11,28}$. We verified that $74 \%$ children with MM who underwent an institutionalized protocol based on the clinical and TUS criteria required VP shunts, which is the same as the percentage of children who underwent CT scan-based protocols ${ }^{11}$. The mean duration of 35 days between the closure of MM and development of hydrocephalus observed in our study was similar to that observed in other studies ${ }^{9,11}$, which emphasizes the importance of regular follow-up, especially in the first 60 days after the closure of MM. However, it should be noted that in some children, hydrocephalus may develop later (within 180 days after the closure of MM).

VP shunt should be considered after a careful clinical and radiological evaluation. According to the results reported here, LVA width of $15 \mathrm{~mm}$, as per the TUS, could be considered as a threshold to classify children with a lower or higher 


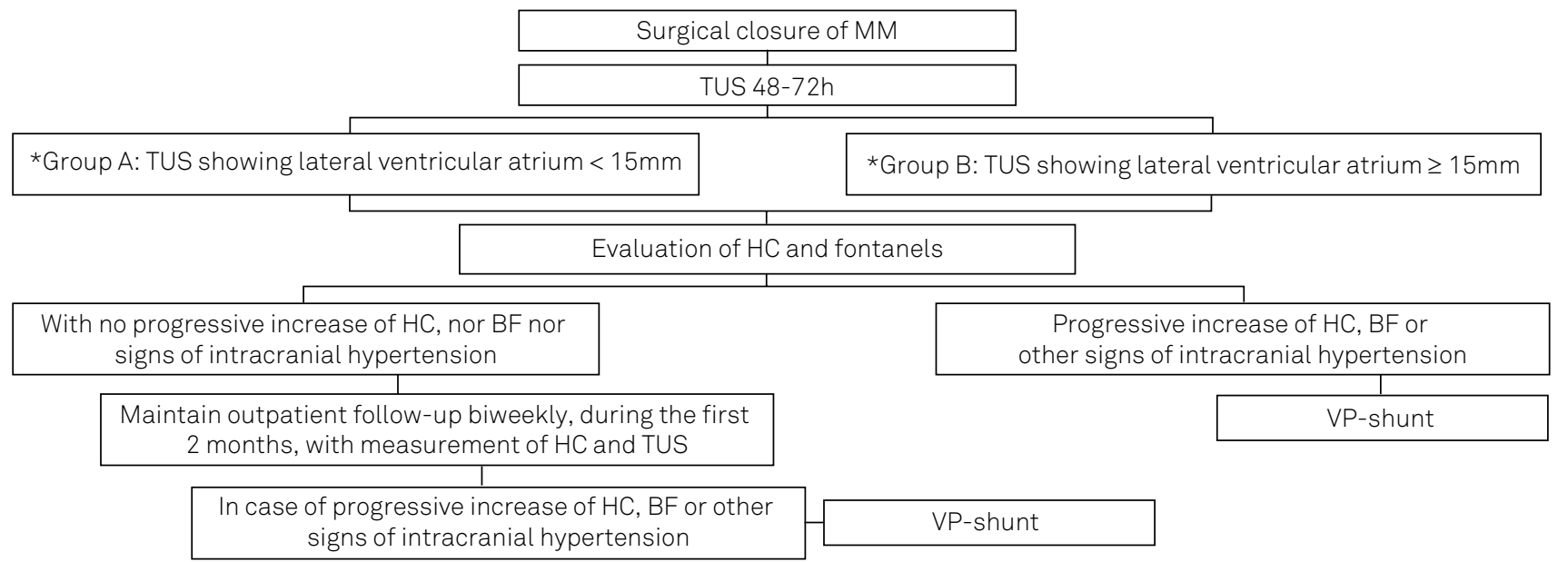

\begin{tabular}{|l|}
\hline $\begin{array}{r}\text { CT scan or MRI in case of signs and symptoms associated with Chiari II malformation or between } 6 \text { and } 12 \text { months of life. } \\
\text { Multidisciplinary follow-up (pediatrician, pediatric neurosurgery, pediatric neurology, } \\
\text { orthopedics, pediatric urology, physiotherapy and pediatric nutrology). }\end{array}$ \\
$\begin{array}{r}\text { Group A }(n=12): 50 \% \text { of incidence of hydrocephalus needs a VP-shunt } \\
\text { Group B }(n=31): 84 \% \text { of incidence of hydrocephalus needs a VP-shunt }\end{array}$ \\
\hline
\end{tabular}

Figure. Protocol for monitoring children with myelomeningocele (MM), considering the risk of developing hydrocephalus, from transcranial ultrasonography (TUS) and clinical criteria (head circumference [HC] and bulging fontanels [BF]).

risk of developing hydrocephalus and requiring VP shunts. Measurement of LVA width by using TUS was performed 48-72 $\mathrm{h}$ after the closure of MM in our study. It was observed that VP shunt were required in $84 \%$ children with LVA width $\geq 15 \mathrm{~mm}$, which was statistically different $(p=0.02)$ from that required by children with lesser LVA width, with a sensitivity of $81 \%$ and a positive predictive value of $84 \%$. Because of the high incidence of hydrocephalus in these children, it is essential to closely monitor them for signs of ICH after the closure of $\mathrm{MM}^{9,11,12,22,26}$. Besides the LVA width measured slightly above the level of the thalami at the level of the choroid plexus, other criteria for hydrocephalus such as bifrontal diameter, bicaudate diameter, diameter of the body of the lateral ventricle, ventricular index, frontooccipital horn ratio, and thalamooccipital distance had already been studied in patients with MM and hydrocephalus ${ }^{11,29}$. Was not the aim of our study comparison between these methods and measures.

In children who still have opened fontanels and sutures, increased $\mathrm{HC}$ and bulging fontanels are the main clinical manifestations ${ }^{11,15,17,19}$ that require imaging methods to confirm the diagnosis and to implement an appropriate treatment $^{11,12,16,17,30}$. In children with greater LVA width $(\geq 15 \mathrm{~mm})$, signs such as progressive increase in $\mathrm{HC}$ or bulging fontanels occur more frequently, which lead to the indication of VP shunts ${ }^{18}$. We emphasize that $6 \%$ of the children who required a VP shunt showed progressive increase in the ventricular system (identified using TUS) without an increase in $\mathrm{HC}$ or bulging fontanels, however showed signs suggestive of neurological impairment due to Chiari II malformation. Other studies also highlight children with signs of ICH but without bulging fontanels ${ }^{11,15}$.

The best surgical time for VP shunt in these children remains unknown (i.e., at the same time of the closure of MM or not). Results of other studies verify that closure of MM and VP shunt sometimes should not be performed in the same surgical time. It is emphasized that concomitant surgeries (closure of MM and VP shunt) should be avoided when MM is corrected $24 \mathrm{~h}$ after birth and that there is a possibility of infection at the site of MM and higher risk of complications associated with the shunt ${ }^{9,12}$. Complications rates were similar to those reported by other authors, considering CSF diversion ${ }^{7,15,17}$.

We recommend that these children should be monitored regularly by a multidisciplinary team in a systematic manner in the long-term mainly due to orthopedic and urinary malformations. Protocols should be followed correctly, according to the possibilities of each region (city, state, or country), to avoid overindication of VP shunt in these children and to avoid systematic realization of CT scan and unnecessary irradiation in these neonates. It should be noted that the results presented here are from a single referral center treating children with $\mathrm{MM}$ and may not reflect the reality in other regions. No single criteria can be considered completely safe, and TUS parameters used in the present study seeks to integrate a possible measure to be used, and under any circumstances overrides other previously published ventricular and ultrasound measurements. We plan to extend the protocol used in this study along with the 
inclusion of transcranial Doppler to figure out the resistive values of the cerebral vascular vessel and in postoperative follow-up study of these children to better identify the functioning of the VP shunts.

In conclusion, definition of criteria that identify children with MM who need a VP shunt is crucial to eliminate unnecessary CSF diversion. By following our institutionalized protocol, we observed that $74 \%$ children who had MM required a VP shunt, which was closely the same observed with other protocols based on CT scan. In our sample VP shunts are usually indicated in children with an LVA width of $\geq 15$ $\mathrm{mm}$, increased HC (2 standard deviations for age), or bulging fontanels. We all know that no method or measure used in isolated form can be considered completely safe. We believe that the measures presented here considering the LVA width can be added to ventricular measurements and parameters previously described in the literature, assisting in the monitoring of children with MM.

\section{References}

1. Adzick NS, Thom EA, Spong CY, Brock JW 3rd, Burrows PK, Johnson MP et al. A randomized trial of prenatal versus postnatal repair of myelomeningocele. N Engl J Med. 2011;364(11):993-1004. doi:10.1056/NEJMoa1014379

2. Bebbington MW, Danzer E, Johnson MP, Adzick NS. Open fetal surgery for myelomeningocele. Prenat Diagn. 2011;31(7):689-94. doi:10.1002/pd.2805

3. Dias MS, Partington M. Embryology of myelomeningocele and anencephaly. Neurosurg Focus. 2004;16(2):1-16. doi:10.3171/foc.2004.16.2.2

4. Talamonti G, D’Aliberti G, Collice M. Myelomeningocele: long-term neurosurgical treatment and follow-up in 202 patients. J Neurosurg. 2007;107(5):368-86. doi:10.3171/PED-07/11/368

5. MRC Vitamin Study Research Group. Prevention of neural tube defects: results of the Medical Research Council Vitamin Study. Lancet. 1991;338(8760):131-7. doi:10.1016/0140-6736(91)90133-A

6. Ryan-Harshman M, Aldoori W. Folic acid and prevention of neural tube defects. Can Fam Physician. 2008;54(1):36-8.

7. Bizzi JWJ, Machado A. [Meningomyelocele: basic concepts and recent advances]. J Bras Neurocirurg. 2012;23(2):138-51. Portuguese.

8. International Clearinghouse for Birth Defects Monitoring Systems, International Centrefor Birth Defects. World atlas of birth defects. 2nd ed. Geneve: World Health Organization; 2003.

9. Chakraborty A, Crimmins D, Hayward R, Thompson D. Toward reducing shunt placement rates in patients with myelomeningocele.J Neurosurg Pediatr. 2008;1 (5):361-5. doi:10.3171/PED/2008/1/5/361

10. Drake JM. The surgical management of Pediatric hydrocephalus. Neurosurgery. 2008;62 Suppl 2:633-40. doi:10.1227/01.neu.0000316268.05338.5b

11. Phillips BC, Gelsomino M, Pownall AL, Ocal E, Spencer HJ, O'Brien MS et al. Predictors of the need for cerebrospinal fluid diversion in patients with myelomeningocele. J Neurosurg Pediatr. 2014;14(2):167-72. doi:10.3171/2014.4.PEDS13470

12. Pinto FCG, Matushita H, Furlan ALB, Alho EJ, Goldenberg DC Bunduki $V$ et al. Surgical treatment of myelomeningocele carried out at 'time zero' immediately after birth. Pediatr Neurosurg. 2009:45(2):114-8. doi:10.1159/000209285

13. Associação Brasileira de Empresa de Pesquisa. Applying Criterion Brazil. São Paulo: Associação Brasileira de Empresa de Pesquisa; data [cited 2013 Jan 8]. Available from: http://www.abep.org/criterio-brasil

14. Righini A, Parazzini C, Doneda C, Arrigoni F, Rustico M, Re TJ et al. Fetal MRI features related to the Chiari malformations. Neurol Sci. 2011;32(3 suppl):279-81. doi:10.1007/s10072-011-0694-1

15. Juca CEB, Lins Neto A, Oliveira RS, Machado HR. [Treatment of hydrocephalus by ventriculoperitoneal shunt: analysis of 150 consecutive cases in the Hospital of the Faculty of Medicine of Ribeirão Preto]. Acta Cirurgica Brasileira. 2002;17 suppl 3:59-63. Portuguese. doi:10.1590/S0102-86502002000900013
16. Mandiwanza T, Saidlear C, Caird J, Crimmins D. The open fontanelle: a window to less radiation. Childs Nerv Syst. 2013;29(7):1177-81. doi:10.1007/s00381-013-2073-0

17. Melo JRT, Melo EN, Vasconcellos A, Pacheco P. Congenital hydrocephalus in the northeast of Brazil: epidemiological aspects, prenatal diagnosis, and treatment. Childs Nerv Syst. 2013;29(10):1989-93. doi:10.1007/s00381-013-2111-y

18. Lee CS, Hong SH, Wang KC, Kin SK, Park JS, Jun JK et al. Fetal ventriculomegaly: prognosis in cases in which prenatal neurosurgical consultation was sought.J Neurosurg Pediatr. 2006;105(4):265-70.

19. Zahl SM, Wester K. Routine measurement of head circumference as a tool for detecting intracranial expansion in infants: what is the gain? a nationwide survey. Pediatrics. 2008;121(3):e416-20. doi:10.1542/peds.2007-1598

20. Renier D, Sainte-Rose C, Pierre-Kahn A, Hirsch JF. Prenatal hydrocephalus: outcome and prognosis. Childs Nerv Syst. 1988;4(4):213-22. doi:10.1007/BF00270917

21. Ros B, Romero L, Ilbañez G, Iglesias S, Rius F, Pérez S et al. Success criteria in pediatric neuroendoscopic procedures. Proposal for classification of results after 67 operations. Childs Nerv Syst. 2012;28(5):691-7. doi:10.1007/s00381-012-1689-9

22. Machado H, Oliveira RS. Simultaneous repair of myelomeningocele and shunt insertion. Childs Nerv Syst. 2004;20(2):107-9. doi:10.1007/s00381-003-0853-7

23. Melo JRT, Pacheco P, Wanderley LE. Unusual spinal dysraphic lesions. Cases Rep Pediatr. 2013(2013):ID210301. doi:10.1155/2013/210301

24. Hamrick SEG. Cesarean delivery and its impact on the anomalous infant. Clin Perinatol. 2008;35(2):395-406. doi:10.1016/j.clp.2008.03.005

25. Lewis D, Tolosa JE, Kaufmann M, Goodman M, Farrell C, Berghella V. Elective cesarean delivery and long-term motor function or ambulation status in infants with meningomyelocele. Obstet Gynecol. 2004;103(3):469-73. doi:10.1097/01.AOG.0000113624.94710.ce

26. Salomao JF, Pinheiro JA, Carvalho JGS, Leibinger RD, Lucchesi G, Bomfim V. [Myelomeningocele: Surgical treatment and results].J Pediatr (Rio J.). 1995;71(6):317-21. doi:10.2223/JPED.799

27. Forgacs P, Geyer CA, Freidberg SR. Characterization of chemical meningitis after neurological surgery. Clin Infect Dis. 2001;32(2):179-85. doi:10.1086/318471

28. Hunt GM, Oakeshott P, Kerry S. Link between the CSF shunt and achievement in adults with spina bifida.J Neurol Neurosurg Psychiatry. 1999;67(5):591-5. doi:10.1136/jnnp.67.5.591

29. Wakhlu A, Ansari NA. The prediction of postoperative hydrocephalus in patients with spina bífida. Childs Nerv Syst. 2004;20(2):104-6. doi:10.1007/s00381-003-0849-31

30. Miller E, Ben-Sira L, Constantini S, Beni-Adani L. Impact of prenatal magnetic resonance imaging on postnatal neurosurgical treatment. J Neurosurg Pediatr. 2006;105(3):203-9. 